\title{
Anthracycline rechallenge using pegylated liposomal doxorubicin in patients with metastatic breast cancer: a pooled analysis using individual data from four prospective trials
}

\author{
S-E Al-Batran*,', M Güntner², C Pauligk', M Scholz², R Chen ${ }^{3}$, B Beiss ${ }^{3}$, S Stopatschinskaja ${ }^{3}$, W Lerbs', \\ N Harbeck ${ }^{4}$ and $E$ Jäger'
}

'Klinik für Onkologie und Hämatologie am Krankenhaus Nordwest, Krankenhaus Nordwest, Steinbacher Hohl 2-26, 60488 Frankfurt am Main, Germany; ${ }^{2}$ Trium Analysis Online GmbH, München, Germany; ${ }^{3}$ Merck, Kenilworth, NJ, USA; ${ }^{4}$ Breast Center, University of Cologne, Cologne, Germany

BACKGROUND: The aim of this study was to determine the activity of anthracycline rechallenge using pegylated liposomal doxorubicin (PLD) in patients with metastatic breast cancer (MBC) previously treated with conventional anthracyclines.

METHODS: Pooled individual data from four prospective trials were used, and the primary end point of the pooled analysis was clinical benefit rate (CBR). The studies comprised 935 patients, of whom 274 had received PLD in the metastatic setting after prior exposure to conventional anthracyclines (rechallenge population).

RESULTS: The majority of patients were heavily pretreated. Previous anthracycline therapy was administered in the adjuvant (I 4\%) or metastatic setting (46\%), or both (40\%). The overall CBR from rechallenge with PLD was 37.2\% (95\% Cl, 32.4-42.0). In univariate analyses, the CBR was significantly higher in patients with less exposure to prior chemotherapy, in taxane-naive patients, and in patients with a favourable Eastern Cooperative Group performance status of 0 vs I vs 2 (53.3 vs 35.5 vs I8.2\%; P<0.00I). In multivariate analyses, performance status proved to be the only independent predictor of the CBR achieved with PLD rechallenge $(P=0.038)$. There was no statistically significant difference in CBR regarding the setting, cumulative dose of and/or resistance to prior anthracyclines, or time since prior anthracycline administration.

CONCLUSION: Anthracycline rechallenge using PLD is effective in patients with MBC who have a favourable performance status, regardless of setting, resistance, cumulative dose or time since prior conventional anthracycline therapy.

British Journal of Cancer (2010) 103, I5 I8-1523. doi: I0.1038/sj.bjc.660596I www.bjcancer.com

Published online 26 October 2010

(C) 2010 Cancer Research UK

Keywords: pegylated liposomal doxorubicin; metastatic breast cancer; anthracycline; rechallenge

In Europe and the United States, breast cancer remains the number one diagnosed cancer in women (incidence rate approximately $28 \%$ ); and in Europe, it is the leading cause of death from cancer in women (Ferlay et al, 2007; Jemal et al, 2009). Though the majority of women with early-stage disease receive adjuvant systemic treatment to prevent disease recurrence, approximately $30-70 \%$ of patients develop metastatic breast cancer (MBC) (Early Breast Cancer Trialists' Group, 2005; Cardoso et al, 2009). MBC patients represent a very heterogeneous population, and the number of available therapies for MBC is rapidly growing. Anthracyclines and taxanes remain the most active cytotoxic agents in the treatment of this disease, and as such, have been widely integrated into adjuvant regimens for early-stage breast cancer (Early Breast Cancer Trialists' Group, 2005; Beslija et al, 2009; Cardoso and Castiglione, 2009; Cardoso et al, 2009).

Clinicians still face a significant challenge in the choice of treatment for patients with $\mathrm{MBC}$ who have failed one or more chemotherapy regimens. The repeated use of conventional anthracyclines is still believed to be limited by cumulative cardiac

*Correspondence: Dr S-E Al-Batran; E-mail: albatran@aol.com Received 27 July 2010; revised 17 September 2010; accepted 24 September 2010; published online 26 October 2010 toxicity (Jones et al, 2006; Ryberg et al, 2008). Doxorubicin cardiotoxicity is dose dependent. The average incidence of doxorubicin-related cardiotoxicity is $5.1 \%$ in women who have received cumulative doses of $400 \mathrm{mg} \mathrm{m}^{-2}$ (Von Hoff et al, 1979; Swain et al, 2003). The incidence of cardiotoxicity exponentially increases with a cumulative dose of $500 \mathrm{mg} \mathrm{m}^{-2}$. This treatmentrelated cardiotoxicity, specifically linked to anthracycline use in these patients, has remained a challenge for physicians, and thus research in this area is increasing.

Because the majority of pretreated patients with $\mathrm{MBC}$ have been exposed to anthracyclines, either in the adjuvant or metastatic settings, there is a need for a cardiac tolerable and effective approach. Pegylated liposomal anthracycline formulations, such as pegylated liposomal doxorubicin (PLD, Caelyx; Schering-Plough, Kenilworth, NJ, USA), represent an attractive option in this setting. Single-agent PLD has repeatedly demonstrated comparable efficacy to doxorubicin, with less cumulative cardiac toxicity and less myelosuppression (Gabizon and Martin, 1997; O'Shaughnessy, 2003; Keller et al, 2004; O'Brien et al, 2004; Theodoulou and Hudis, 2004). Moreover, data suggest efficacy of PLD in the anthracycline rechallenge setting (Keller et al, 2004; O'Brien et al, 2004; Al-Batran et al, 2006a, b; Trudeau et al, 2009).

There is no consensus about which parameters should be used in the decision regarding anthracycline rechallenge. Criteria 
clinicians need to consider include prior anthracycline treatment, prior taxane exposure, previous radiation, patient performance status, cardiac history and cardiac function, age and other co-variants. Two important factors, time since prior anthracycline therapy and cumulative dose of anthracycline, have been identified as predictive factors for the efficacy of anthracycline rechallenge in some studies; however, they have not been validated (Singal and Iliskovic, 1998).

Thus, we conducted a pooled analysis on individual patient data of $\mathrm{MBC}$ populations who received single-agent PLD rechallenge after previous exposure to conventional anthracyclines. The primary objective was clinical benefit rate (CBR). The secondary objective was to determine clinical factors that may predict the efficacy of PLD in anthracycline-pretreated patients with MBC.

\section{MATERIALS AND METHODS}

\section{Literature search and identification of studies}

The aim of this study was to identify all relevant published prospective randomised clinical trials evaluating PLD as monotherapy in patients with MBC. A literature search was performed using databases (PubMed, CANCERLIT, the Cochrane Library and clinicaltrials.gov).

\section{Study selection}

Eligible trials were prospective, in which patients received singleagent PLD for metastatic disease and included at least a subgroup of patients who had been pretreated with conventional anthracyclines. Four trials were identified from these searches for inclusion (Table 1; Keller et al, 2004; O'Brien et al, 2004; Al-Batran et al, $2006 \mathrm{a}, \mathrm{b})$. The databases of these studies were provided by Merck, formerly Schering Plough Corp. The analysis was performed with the permission of the ethics committee responsible for our institution.

\section{Study objectives and data extraction}

The primary end point, CBR, was defined as objective response, which included complete response, partial response or stable disease lasting longer than 6 months. Rechallenge with PLD was considered efficacious if the CBR exceeded $30 \%$, whereas below $20 \%$ was considered inactive. The rate of $30 \%$ was considered clinically relevant taking into account the heavily pretreated population. Post hoc calculations provided $98 \%$ power to detect a CBR rate $>30 \%$ (A'Hern, 2001).

Pre-specified clinical parameters, including baseline Eastern Cooperative Group (ECOG) performance status, number of previous chemotherapies, previous taxane, age, setting of prior anthracycline, cumulative dose of prior anthracycline, anthracycline-free interval and anthracycline resistance were evaluated for their association with the CBR, response rate (RR), progressionfree survival (PFS) and overall survival (OS). Anthracycline resistance was defined as having disease progression while on anthracycline-based therapy for metastatic disease, or within 6 months of receiving adjuvant anthracycline treatment.

Table 2 Distribution of predefined clinical parameters

\begin{tabular}{|c|c|}
\hline & $N(\%)$ \\
\hline \multicolumn{2}{|l|}{ Age } \\
\hline $18-65$ years & $222(81.0)$ \\
\hline$>65$ years & $52(19.0)$ \\
\hline \multicolumn{2}{|c|}{ ECOG performance status } \\
\hline 0 & $75(27.4)$ \\
\hline । & $154(56.2)$ \\
\hline 2 & $44(16.0)$ \\
\hline Unknown & I (0.4) \\
\hline \multicolumn{2}{|l|}{ No. of prior therapies ${ }^{\text {a }}$} \\
\hline I & $18(6.6)$ \\
\hline 2 & $62(22.6)$ \\
\hline$>2$ & $194(70.8)$ \\
\hline \multicolumn{2}{|l|}{ Previous taxane } \\
\hline Yes & $198(72.3)$ \\
\hline No & $66(24.1)$ \\
\hline Unknown & $10(3.6)$ \\
\hline \multicolumn{2}{|c|}{ Anthracycline-free interval } \\
\hline $0-12$ months & $96(35.1)$ \\
\hline$>12$ months & $150(54.7)$ \\
\hline Unknown & $28(10.2)$ \\
\hline \multicolumn{2}{|c|}{ Setting of prior anthracycline exposure } \\
\hline Adjuvant only & $38(13.9)$ \\
\hline Metastatic only & $126(46.0)$ \\
\hline Both & $110(40.1)$ \\
\hline \multicolumn{2}{|c|}{ Cumulative dose of prior anthracycline } \\
\hline$<180 \mathrm{mg} \mathrm{m}^{-2}$ & $79(28.8)$ \\
\hline $180-250 \mathrm{mg} \mathrm{m}^{-2}$ & $73(26.7)$ \\
\hline$>250 \mathrm{mg} \mathrm{m}^{-2}$ & $88(32.1)$ \\
\hline Unknown & $34(12.4)$ \\
\hline \multicolumn{2}{|l|}{ Anthracycline resistance } \\
\hline Yes & $118(43.1)$ \\
\hline No & $138(50.4)$ \\
\hline Unknown & $18(6.5)$ \\
\hline
\end{tabular}

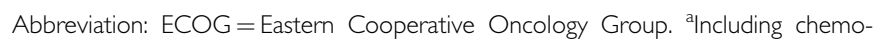
therapy and hormonal therapy in the adjuvant and metastatic setting.

Table I Trial characteristics

\begin{tabular}{|c|c|c|c|c|}
\hline & Al-Batran et al (2006a) & Al-Batran et al (2006b) & Keller et al (2004) & O'Brien et al (2004) \\
\hline $\begin{array}{l}\text { Date first patient enroled } \\
\text { No. of patients }\end{array}$ & May 2000 & October 2001 & June 1997 & June 1998 \\
\hline $\begin{array}{l}\text { Total/received PLD/received } \\
\text { PLD after prior CAC }\end{array}$ & 79/79/79 & $46 / 46 / 33$ & $301 / 150 / 124$ & $509 / 254 / 38$ \\
\hline Study design & Non-randomised phase II & Non-randomised phase II & $\begin{array}{l}\text { Randomised phase III with PLD vs } \\
\text { comparator }^{\text {a }}\end{array}$ & $\begin{array}{l}\text { Randomised phase III with } \\
\text { PLD vs doxorubicin }\end{array}$ \\
\hline Study population & $\begin{array}{l}\text { Women with at least I prior } \\
\text { chemotherapy for } \mathrm{MBC}\end{array}$ & $\begin{array}{l}\text { Women with at least I prior } \\
\text { chemotherapy for } \mathrm{MBC}\end{array}$ & $\begin{array}{l}\text { Women with taxane refractory } \mathrm{MBC} \\
\text { and } \leqslant 2 \text { prior chemotherapies for } \\
\text { metastatic disease }\end{array}$ & $\begin{array}{l}\text { Women, previously untreated } \\
\text { for metastatic disease }\end{array}$ \\
\hline Response assessment scale & $\mathrm{WHO}$ & $\mathrm{WHO}$ & NK & WHO \\
\hline PLD schedule & $50 \mathrm{mg} \mathrm{m}^{-2}$ every 4 weeks & $40 \mathrm{mg} \mathrm{m}^{-2}$ every 4 weeks & $50 \mathrm{mg} \mathrm{m}^{-2}$ every 4 weeks & $50 \mathrm{mg} \mathrm{m}^{-2}$ every 4 weeks \\
\hline
\end{tabular}

Abbreviations: PLD = pegylated liposomal doxorubicin; MBC = metastatic breast cancer; CAC = conventional anthracycline; WHO World Health Organization; NK= not known. ${ }^{a}$ Vinorelbine or mitomycin $C$ plus vinblastine. 


\section{Statistical analysis}

Heterogeneity between studies was tested using the log-rank test for PFS and OS and the Fisher's exact test for CBR, RR and baseline parameters. The same statistical tests and models were applied to assess the univariate relationship between predefined variables and the primary and secondary end points. Furthermore, Cox proportional hazard models and logistic regression models were used for the multivariate analysis. In a secondary analysis, the univariate results were adjusted for baseline performance status, prior taxane therapy and number of previous chemotherapy regimens (these factors were found to be heterogeneous among the populations). Time-to-event curves was calculated by the Kaplan-Meier method. All $P$-values were two sided, with $P$-values $<0.05$ considered to indicate statistical significance.

\section{RESULTS}

\section{Characteristics of the patients}

Of the 935 patients included in this analysis, 274 (29.3\%) received PLD and had at least one prior conventional anthracycline therapy. The distribution of the predefined clinical parameters in the pooled population is shown in Table 2 . The median age of the patients was 56 years (range, 29-87 years). Patients had a median of 3.5 prior treatment lines (range, 1-9), and $93.4 \%$ had at least two previous therapies (including chemotherapy and hormonal therapy). Prior anthracycline therapy was mostly administered in the metastatic setting, with prior anthracycline being adjuvant (14\%), metastatic $(46 \%)$ or in both settings (40\%). Patients received a median of three cycles of PLD (range, 1-18), with a median dose of $83.8 \mathrm{mg}$ per cycle and a mean cumulative dose of

Table 3 Clinical benefit rate

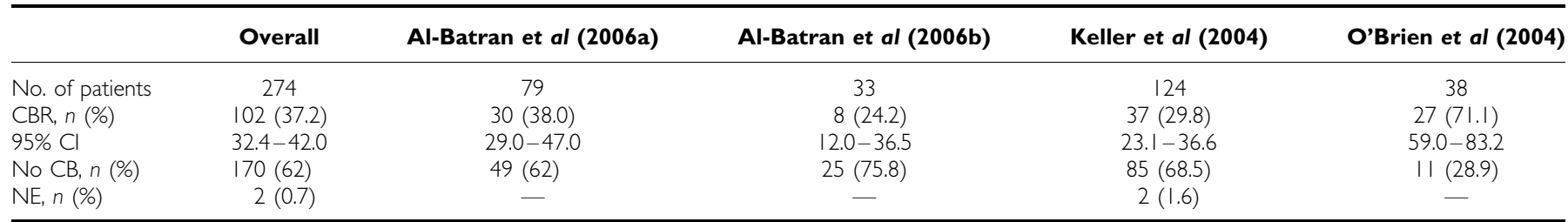

Abbreviations: $\mathrm{CBR}=$ clinical benefit rate; $\mathrm{CB}=$ clinical benefit; $\mathrm{NE}=$ not evaluable for clinical benefit.

Table 4 Univariate analysis of outcomes according to clinical parameters

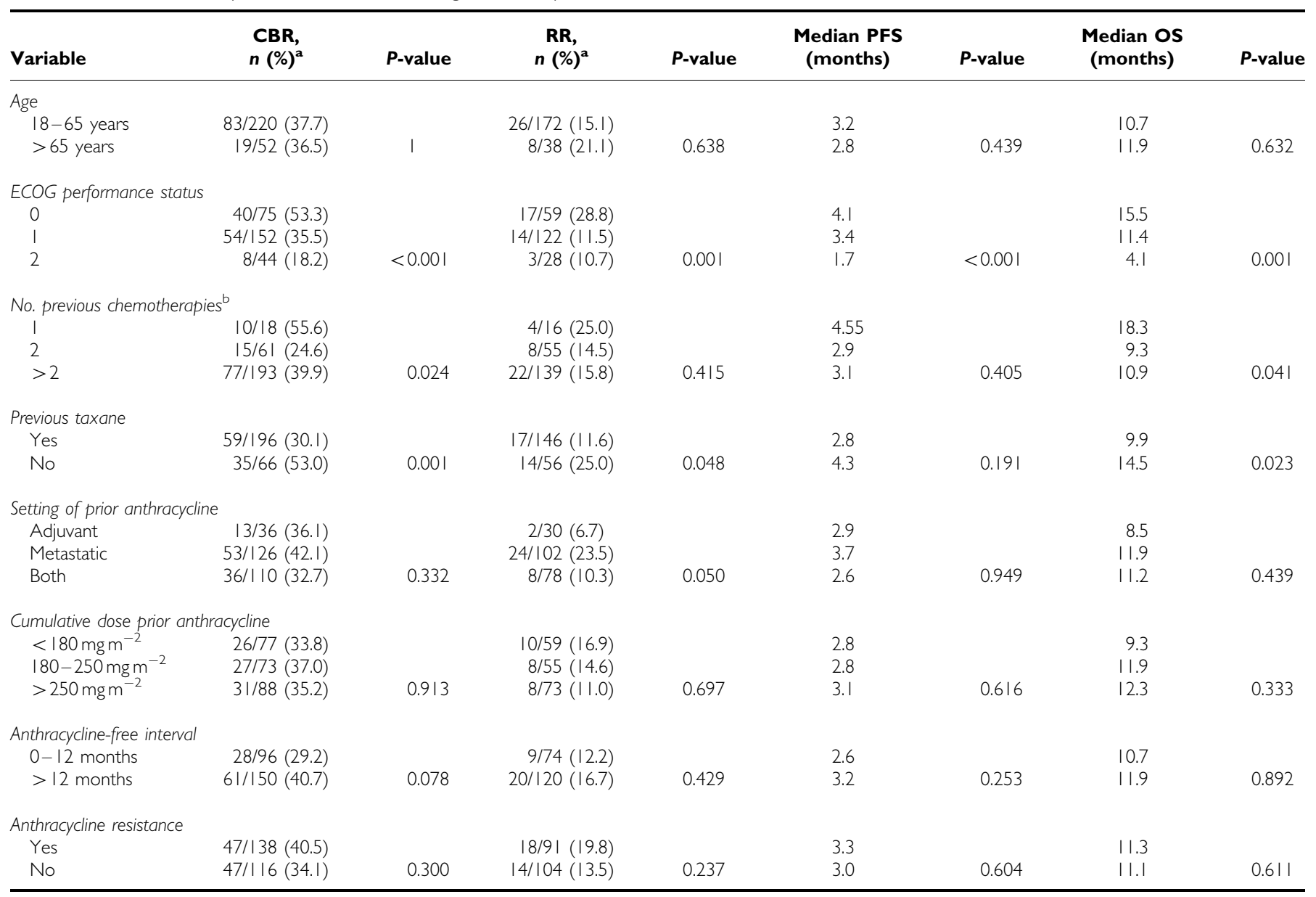

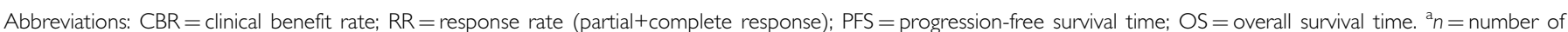
patients who were evaluable for predefined parameter and end point. ' Including chemotherapy and hormonal therapy in the adjuvant and metastatic setting. 
$311 \mathrm{mg}$ (range, $25.5-1394 \mathrm{mg}$ ). There was significant heterogeneity between the studies regarding baseline ECOG performance status, taxane pretreatment and number of prior chemotherapy regimens. This heterogeneity was found to be attributed to the study by O'Brien et al (2004), which enrolled patients previously untreated in the metastatic setting (Table 1).

\section{Overall clinical benefit rate}

Clinical benefit rate is shown in Table 3 (O'Brien et al, 2004; Keller et al, 2004; Al-Batran et al, 2006a,b). The overall CBR was $37.2 \%$ (95\% CI, 32.4-42.0). The lower boundary of the $95 \%$ confidence interval of the CBR observed was above the pre-defined $30 \%$ rate. The logistic regression model showed a higher CBR in the study by O'Brien $(P<0.001)$ as compared with the study by Keller. In the pooled population, median PFS and OS were 3 (95\% CI, 2.8-3.7 months) and 11.1 months (95\% CI, 8.9-13.1 months), respectively.

\section{Outcomes according to clinical parameters: univariate analyses}

Clinical benefit rate, RR, PFS and OS according to clinical parameters are shown in Table 4. There was no difference in CBR between patients who were considered anthracycline resistant and those who were not $(40.5$ vs $34.1 \% ; P=0.300)$. There also was no difference in CBR between patients who received prior anthracycline in the adjuvant setting (34.2\%), in the metastatic setting $(42.1 \%)$, or both settings $(32.7 \%), P=0.332$. There were no significant differences in CBR between patients who had low, medium or high cumulative doses of prior anthracycline at baseline (33.8 vs 37.0 vs $35.2 \%$, respectively; $P=0.913$ ). A trend towards higher CBR was detected in patients who received PLD $>12$ months $v s \leqslant 12$ months since the end of their prior anthracycline therapy (40.7 vs $29.2 \% ; P=0.078)$. The adjustment for ECOG performance status, taxane pretreatment and number of prior chemotherapies revealed similar results (data not shown).

Among clinical parameters not associated with prior anthracycline therapy, ECOG performance status was the strongest predictor of clinical benefit; CBR was 53.3, 35.5 and $18.2 \%$ in patients with ECOG performance status of 0,1 and 2, respectively $(P<0.001)$. In addition, a statistically significant higher RR, longer PFS and OS were observed for patients with ECOG performance status of 0 and 1 vs 2 (Table 4; Figure 1). Significantly higher CBRs were also observed in taxane-naive patients $(53.0 \%)$ vs patients who received a previous taxane $(30.1 \%), P=0.001$, and in patients who failed only one therapy $v s$ more than one therapy (1 vs 2 vs 3: 55.6 vs 24.6 vs $39.9 \%$, respectively; $P=0.024$ ). Age was not a predictor of CBR. The univariate results regarding CBR were adjusted for ECOG performance status, taxane pretreatment and number of prior chemotherapies using a logistic regression model. The results were similar to the unadjusted models (data not shown).

\section{Multivariate analyses}

All clinical parameters were included in a logistic regression model to determine their predictive effect on CBR. ECOG performance status was a strong predictor of CBR $(P=0.038)$. The number of prior chemotherapies was no longer a significant predictor of CBR $(P=0.192)$, and taxane pretreatment showed a non-significant trend $(P=0.072)$. None of the other clinical parameters was statistically significant. In a multivariate Cox regression analysis, ECOG performance status also was a significant predictor of PFS $(P=0.002)$ and OS $(P<0.001)$. The number of prior chemotherapies was a significant predictor of OS $(P=0.041)$.

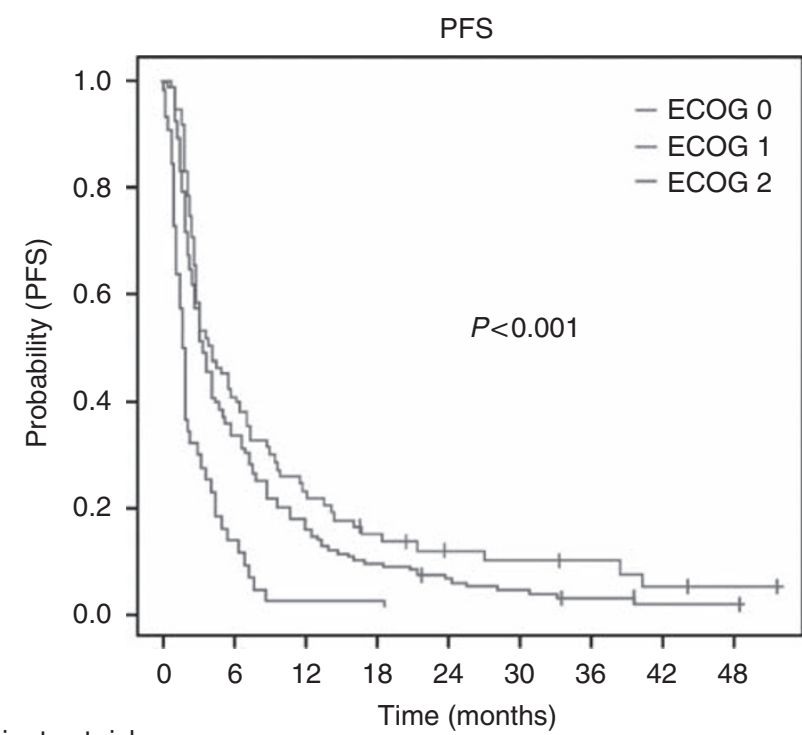

Patients at risk:

$\begin{array}{lccccccccc}\text { ECOG 0 } & 75 & 56 & 44 & 27 & 17 & 10 & 7 & 3 & 1 \\ \text { ECOG } 1 & 152 & 107 & 68 & 44 & 27 & 17 & 8 & 3 & 1 \\ \text { ECOG } 2 & 44 & 18 & 7 & 4 & 1 & 1 & 1 & 0 & 0\end{array}$

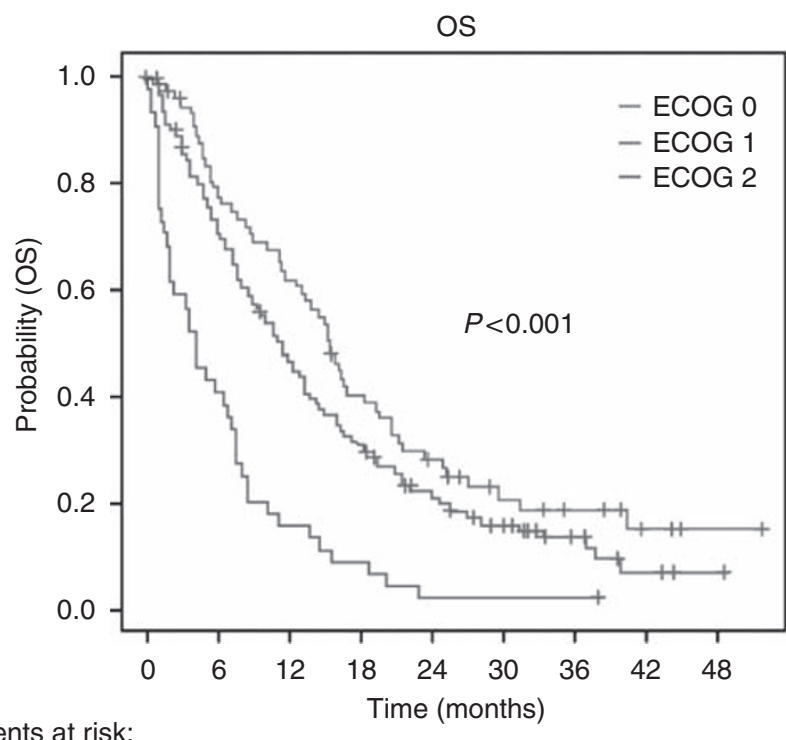

Patients at risk:

$\begin{array}{lccccccccc}\text { ECOG 0 } & 75 & 30 & 17 & 10 & 6 & 5 & 4 & 2 & 1 \\ \text { ECOG 1 } & 152 & 51 & 25 & 14 & 10 & 6 & 3 & 1 & 1 \\ \text { ECOG 2 } & 44 & 6 & 1 & 1 & 0 & 0 & 0 & 0 & 0\end{array}$

Figure I Progression-free and overall survival under pegylated liposomal doxorubicin therapy in patients previously treated with conventional anthracyclines Eastern Cooperative Oncology Group performance status.

\section{DISCUSSION}

This pooled analysis on the largest data set of MBC patients who were pretreated with an anthracycline evaluates the efficacy of anthracycline rechallenge using PLD. All patients had received conventional anthracyclines, and $72 \%$ had received prior taxane therapy. The majority were pretreated with more than one line of chemotherapy for metastatic disease. Therefore, most patients in this analysis were in an advanced and palliative course of their disease when they received PLD as an anthracycline rechallenge. Accordingly, we chose CBR as the primary end point for this patient population rather than RR or PFS (Ohorodnyk et al, 2009). 
A clinical benefit is achieved when either an objective response or a long-lasting stable disease is documented. This reflects a direct and real effect of the rechallenge. Overall survival was not selected as the primary objective because it is influenced by other parameters such as further therapies and prognostic factors (Saad et al, 2010). The primary assumption of this study, that CBR $>30 \%$, was met in this analysis, where $37.2 \%$ of patients exhibited a clinical benefit from rechallenge with PLD (95\% CI, 32.4-42.0). In the univariate analysis, patients with less exposure to prior treatment (i.e., one prior regimen or taxane naive) exhibited a statistically significantly higher CBR $(53-56 \%)$ than patients that had received two or more prior regimens or prior taxane (25-36\%). Moreover, patients with a favourable ECOG performance status ( 0 or 1$)$ exhibited a statistically significantly higher CBR than patients with impaired ECOG performance status (2) (36-53 vs $18.2 \%$, respectively).

In the multivariate analysis, ECOG performance status was determined to be the only independent predictor of the efficacy of anthracycline rechallenge with PLD. The ECOG performance status is widely used to quantify the functional status of cancer patients and is a common and consistent prognostic factor (Yates et al, 1980). However, the ECOG performance status can also predict the efficacy of a particular treatment, as patients with a better performance status are more likely to be compliant and maintain treatment duration and dose intensity (Nash et al, 1980; Sjöström and Blomqvist, 1996; Robain et al, 2000).

In contrast, no statistically significant differences in CBR were found in this pooled analysis for the following predefined parameters related to prior anthracycline therapy: (1) treatment setting for prior anthracycline administration, (2) anthracycline cumulative dose, (3) resistance to anthracycline and (4) anthracycline-free interval. These results translate into an expected significant efficacy from PLD rechallenge if the patient has an ECOG performance status of 0 or 1 (or conversely a poor efficacy if the patient has an ECOG performance status of 2), regardless of the number and type of prior therapies as well as prior anthracycline exposure. Notably, the lack of association between efficacy of anthracycline rechallenge and the parameters related to prior anthracycline therapy apply to the threshold definitions used in our study. It is possible that if alternative thresholds were used for the definitions of our parameters, then we would have encountered a different result in this analysis. Overall, the results of our study support the need to identify molecular-based predictive factors for anthracycline efficacy (Pritchard et al, 2008; Gianni et al, 2009).

In the recent literature, the rates of clinical benefit achieved with combination therapies in MBC patients varied between 39 and $80 \%$ in first-line patients, and 34 and $71 \%$ in patients previously treated for metastatic disease (Blum et al, 2006; Moulder et al, 2008; Silva et al, 2008; Osako et al, 2009; Ciruelos et al, 2010; Tan et al, 2010). Therefore, given the characteristics of our population and that single-agent therapy was used, the overall CBR of $37 \%$ observed in our study, is clinically meaningful and supports efficacy of an anthracycline rechallenge with PLD. This finding is in agreement with published reports that show activity and support the use of anthracyclines in anthracycline-pretreated patients (Gennari et al, 2004; Beslija et al, 2009; Katsumata et al, 2009; Krell et al, 2009). Notably, this analysis was not specifically designed to address the question of the first-line use of PLD after adjuvant anthracyclinebased therapy. In the first-line setting, higher objective response and CBRs are observed after anthracycline rechallenge with PLD-containing combination chemotherapy (Overmoyer et al, 2005; Sparano et al, 2009; Trudeau et al, 2009).

The important question from findings of our pooled analysis is how these results fit into the evolving individualised field of chemotherapy for women with MBC. The ever-growing options for treatment coupled with biologically tailored research pose a challenge for clinicians. As a result, oncologists are increasingly shifting towards a more individualised treatment strategy based on factors such as patient and tumour characteristics, patient input and prior therapies. Our study justifies considering anthracycline rechallenge with PLD as one option for patients with MBC, who failed conventional anthracyclines or more agents in the adjuvant, metastatic or both settings, if the performance status of the patients is still favourable (i.e., ECOG performance status 0 or 1).

\section{ACKNOWLEDGEMENTS}

This analysis was supported by a grant from Schering-Plough Corporation. We thank Karin Scheffler for her assistance in data management and preparation of the article. We thank Claire Gilmore from the Phillips Group for editorial assistance with this article. The authors take full responsibility for the content of this publication.

\section{REFERENCES}

A'Hern RP (2001) Sample size tables for exact single-stage phase II designs. Stat Med 20: 859-866

Al-Batran SE, Bischoff J, von Minckwitz G, Atmaca A, Kleeberg U, Meuthen I, Morack G, Lerbs W, Hecker D, Sehouli J, Knuth A, Jager E (2006a) The clinical benefit of pegylated liposomal doxorubicin in patients with metastatic breast cancer previously treated with conventional anthracyclines: a multicentre phase II trial. Br J Cancer 94: 1615-1620

Al-Batran SE, Meerpohl HG, von Minckwitz G, Atmaca A, Kleeberg U, Harbeck N, Lerbs W, Hecker D, Sehouli J, Knuth A, Jager E (2006b) Reduced incidence of severe palmar-plantar erythrodysesthesia and mucositis in a prospective multicenter phase II trial with pegylated liposomal doxorubicin at $40 \mathrm{mg} / \mathrm{m}^{2}$ every 4 weeks in previously treated patients with metastatic breast cancer. Oncology 70: 141-146

Beslija S, Bonneterre J, Burstein HJ, Cocquyt V, Gnant M, Heinemann V, Jassem J, Köstler WJ, Krainer M, Menard S, Petit T, Petruzelka L, Possinger K, Schmid P, Stadtmauer E, Stockler M, Van Belle S, Vogel C, Wilcken N, Wiltschke C, Zielinski CC, Zwierzina H (2009) Third consensus on medical treatment of metastatic breast cancer. Ann Oncol 20: $1771-1785$

Blum JL, Dees EC, Chacko A, Doane L, Ethirajan S, Hopkins J, McMahon R, Merten S, Negron A, Neubauer M, Ilegbodu D, Boehm KA, Asmar L,

O'Shaughnessy JA (2006) Phase II trial of capecitabine and weekly paclitaxel as first-line therapy for metastatic breast cancer. J Clin Oncol 24: $4384-4390$

Cardoso F, Bedard PL, Winer EP, Pagani O, Senkus-Konefka E, Fallowfield LJ, Kyriakides S, Costa A, Cufer T, Albain KS (2009) International guidelines for management of metastatic breast cancer: combination $v s$ sequential single-agent chemotherapy. J Natl Cancer Inst 101: 1174-1181

Cardoso F, Castiglione M (2009) Locally recurrent or metastatic breast cancer: ESMO clinical recommendations for diagnosis, treatment and follow-up. Ann Oncol 4(Suppl): 15-18

Ciruelos EM, Cortés J, Cortés-Funes H, Mayordomo JI, Bermejo B, Ojeda B, García E, Rodríguez CA, Muñoz M, Gómez P, Manso L, Andrés R, Lluch A, Saura C, Mendiola C, Baselga J (2010) Gemcitabine and capecitabine in previously anthracycline-treated metastatic breast cancer: a multicenter phase II study (SOLTI 0301 trial). Ann Oncol 21: $1442-1447$

Early Breast Cancer Trialists' Group (2005) Effects of chemotherapy and hormonal therapy for early breast cancer on recurrence and 15-year survival: an overview of the randomized trials. Lancet 365: 1687-1717

Ferlay J, Autier P, Boniol M, Heanue M, Colombet M, Boyle P (2007) Estimates of the cancer incidence and mortality in Europe in 2006. Ann Oncol 18: 581 - 592 
Gabizon A, Martin F (1997) Polyethylene glycol-coated (pegylated) liposomal doxorubicin: rationale for use in solid tumours. Drugs 54: 15-21

Gennari A, Bruzzi P, Orlandini C, Salvadori B, Donati S, Landucci E, Guarneri V, Rondini M, Ricci S, Conte P (2004) Activity of first line epirubicin and paclitaxel in metastatic breast cancer is independent from type of adjuvant therapy. Br J Cancer 90: $962-967$

Gianni L, Norton L, Wolmark N, Suter TM, Bonadonna G, Hortobagyi GN (2009) Role of anthracyclines in the treatment of early breast cancer. J Clin Oncol 27: 4798-4808

Jemal A, Siegel R, Ward E, Hao Y, Xu J, Thun MJ (2009) Cancer statistics, 2009. CA Cancer J Clin 59: 225-249

Jones RL, Swanton C, Ewer MS (2006) Anthracycline cardiotoxicity. Expert Opin Drug Saf 5: 791-809

Katsumata N, Watanabe T, Minami H, Aogi K, Tabei T, Sano M, Masuda N, Andoh J, Ikeda T, Shibata T, Takashima S (2009) Phase III trial of doxorubicin plus cyclophosphamide (AC), docetaxel, and alternating $\mathrm{AC}$ and docetaxel as front-line chemotherapy for metastatic breast cancer: Japan Clinical Oncology Group trial (JCOG9802). Ann Oncol 20: 1210 - 1215

Keller AM, Mennel RG, Georgoulias VA, Nabholtz JM, Erazo A, Lluch A, Vogel CL, Kaufmann M, von Minckwitz G, Henderson IC, Mellars L, Alland L, Tendler C (2004) Randomized phase III trial of pegylated liposomal doxorubicin $v s$ vinorelbine or mitomycin $\mathrm{C}$ plus vinblastine in women with taxane-refractory advanced breast cancer. J Clin Oncol 22: $3893-3901$

Krell J, Harper-Wynne C, Miles D, Misra V, Cleator S, Krell D, Palmier D (2009) What is the evidence for rechallenging with anthracyclines or taxanes in metastatic breast cancer? A review of the data. J Clin Oncol 27(15S): 1072

Moulder S, Valkov N, Neuger A, Choi J, Lee JH, Minton S, Munster P, Gump J, Lacevic M, Lush R, Sullivan D (2008) Phase 2 study of gemcitabine and irinotecan in metastatic breast cancer with correlatives to determine topoisomerase I localization as a predictor of response. Cancer 113: $2646-2654$

Nash III CH, Jones S, Moon TE, Davis SL, Salmon SE (1980) Prediction of outcome in metastatic breast cancer treated with adriamycin combination chemotherapy. Cancer 46: 2380-2388

O’Brien ME, Wigler N, Inbar M, Rosso R, Grischke E, Santoro A, Catane R, Kieback DG, Tomczak P, Ackland SP, Orlandi F, Mellars L, Alland L, Tendler C (2004) Reduced cardiotoxicity and comparable efficacy in a phase III trial of pegylated liposomal doxorubicin HCl (CAELYX/Doxil) $v s$ conventional doxorubicin for first-line treatment of metastatic breast cancer. Ann Oncol 15: 440-449

O'Shaughnessy JA (2003) Pegylated liposomal doxorubicin in the treatment of breast cancer. Clin Breast Cancer 4: 318-328

Ohorodnyk P, Eisenhauer EA, Booth CM (2009) Clinical benefit in oncology trials: is this a patient-centred or tumour-centred end-point? Eur J Cancer 45: 2249-2252

Osako T, Ito $\mathrm{Y}$, Ushijima M, Takahashi S, Tokudome $\mathrm{N}$, Sugihara $\mathrm{T}$, Iwase T, Matsuura M, Hatake K (2009) Predictive factors for efficacy of capecitabine in heavily pretreated patients with metastatic breast cancer. Cancer Chemother Pharmacol 63: 865-871

Overmoyer B, Silverman P, Holder LW, Tripathy D, Henderson IC (2005) Pegylated liposomal doxorubicin and cyclophosphamide as first-line therapy for patients with metastatic or recurrent breast cancer. Clin Breast Cancer 6: 150 - 157
Pritchard KI, Messersmith H, Elavathil L, Trudeau M, O'Malley F, Dhesy-Thind B (2008) HER-2 and topoisomerase II as predictors of response to chemotherapy. J Clin Oncol 26: 736-744

Robain M, Pierga JY, Jouve M, Asselain B, Diéras V, Beuzeboc P, Palangié T, Dorval T, Extra JM, Scholl S, Pouillart P (2000) Predictive factors of response to first-line chemotherapy in 1426 women with metastatic breast cancer. Eur J Cancer 36: 2301-2312

Ryberg M, Nielsen D, Cortese G, Nielsen G, Skovsgaard T, Andersen PK (2008) New insight into epirubicin cardiac toxicity: competing risks analysis of 1097 breast cancer patients. J Natl Cancer Inst 100: 1058 - 1067

Saad ED, Katz A, Hoff PM, Buyse M (2010) Progression-free survival as surrogate and as true endpoint: insights from the breast and colorectal cancer literature. Ann Oncol 21: 7-12

Silva O, Lopes G, Morgenzstern D, Lobo C, Doliny P, Santos E, Abdullah S, Gautam U, Reis I, Welsh C, Slingerland J, Hurley J, Gluck S (2008) A phase II trial of split, low-dose docetaxel and low-dose capecitabine: a tolerable and efficacious regimen in the first-line treatment of patients with HER2/neu-negative metastatic breast cancer. Clin Breast Cancer 8: $162-167$

Singal PK, Iliskovic N (1998) Doxorubicin-induced cardiomyopathy. N Engl I Med 39: 900 - 905

Sjöström J, Blomqvist C (1996) Predictive factors for response to cytotoxic treatment in advanced breast cancer: a review. Acta Oncol 5(Suppl 35): $84-90$

Sparano JA, Makhson AN, Semiglazov VF, Tjulandin SA, Balashova OI, Bondarenko IN, Bogdanova NV, Manikhas GM, Oliynychenko GP, Chatikhine VA, Zhuang SH, Xiu L, Yuan Z, Rackoff WR (2009) Pegylated liposomal doxorubicin plus docetaxel significantly improves time to progression without additive cardiotoxicity compared with docetaxel monotherapy in patients with advanced breast cancer previously treated with neoadjuvant-adjuvant anthracycline therapy: results from a randomized phase III study. J Clin Oncol 27: $4522-4529$

Swain SM, Whaley FS, Ewer MS (2003) Congestive heart failure in patients treated with doxorubicin: a retrospective analysis of three trials. Cancer 97: $2869-2879$

Tan WW, Hillman DW, Salim M, Northfelt DW, Anderson DM, Stella PJ, Niedringhaus R, Bernath AM, Gamini SS, Palmieri F, Perez EA (2010) N0332 phase 2 trial of weekly irinotecan hydrochloride and docetaxel in refractory metastatic breast cancer: a North Central Cancer Treatment Group (NCCTG) Trial. Ann Oncol 21: 493-497

Theodoulou M, Hudis C (2004) Cardiac profiles of liposomal anthracyclines. Cancer 100: 2052-2063

Trudeau ME, Clemons MJ, Provencher L, Panasci L, Yelle L, Rayson D, Latreille J, Vandenberg T, Goel R, Zibdawi L, Rahim Y, Pouliot JF (2009) Phase II multicenter trial of anthracycline rechallenge with pegylated liposomal doxorubicin plus cyclophosphamide for first-line therapy of metastatic breast cancer previously treated with adjuvant anthracyclines. J Clin Oncol 27: 5906-5910

Von Hoff DD, Layard MW, Basa P, Davis Jr HL, Von Hoff AL, Rozencweig M, Muggia FM (1979) Risk factors for doxorubicin-induced congestive heart failure. Ann Intern Med 91: 710-717

Yates JW, Chalmer B, McKegney FP (1980) Evaluation of patients with advanced cancer using the Karnofsky performance status. Cancer 45: $2220-2224$ 